\title{
Application of Ecological Architecture Concepts to Industrial Villages in Surabaya (Case Study: Gundih Village)
}

\section{Penerapan Konsep Arsitektur Ekologi Pada Kampung Industri Di Surabaya (Studi Kasus: Kampung Gundih)}

\author{
Dian P.E. Laksmiyanti ${ }^{1}$, Esty Poedjioetami ${ }^{1}$ \\ ${ }^{1}$ Jurusan Arsitektur \\ Institut Teknologi Adhi Tama Surabaya, Jl. Arief Rahman Hakim no 100, Surabaya. Kode pos: 60117 \\ email : dianpramita@itats.ac.id (corresponding author) \\ doi: https://doi.org/10.31315/opsi.v14i1.3958
}

Received: $21^{\text {st }}$ November 2020; Revised: $18^{\text {th }}$ December 2020; Accepted: $11^{\text {th }}$ June 2021;

Available online: $24^{\text {th }}$ June 2021; Published regularly: June 2021

\begin{abstract}
Global warming encourage people to care more about energy consumption. Metropolitan city like Surabaya has a complex problem in it such as high density, fast growth and development, high energy consumption, and many more. Ecological city supposed to encourage smart citizen, environmentally friendly and humane. It obviously not easy, requires good cooperation between the government, sector managers and the community. The Surabaya mayor's approach and the socialization of the importance of implementing green architecture in each area have succeeded in raising public awareness to create a harmonious, ecological and energy-conscious environment. Apart from the ecological aspects, what makes Surabaya the most advanced city in Indonesia is economic growth. The fast economic growth cannot be separated from the motivation of the Mayor of Surabaya in growing small and medium industries. Kampung Gundih is one of the kampong that has successfully implemented the ecological concept and has become the most advanced home industry in Surabaya by winning the Surabaya Green and Clean in recent years. This study aims to identify and describe the application of Green architecture and ecological concepts in small industrial-based settlements in Kampung Gundih, Surabaya. The method used in this research is descriptive qualitative. The results obtained are a review of the implementation of the concept of ecological architecture in rural areas and small industries, a description of the integrated water management process, and environmental management strategies in Kampung Gundih Surabaya.
\end{abstract}

Keywords: Ecological Architecture ; Environment management ; Home Industry ; Kampong

\begin{abstract}
ABSTRAK
Laju pemakaian energi yang cukup besar membuat masyarakat mulai menyadari akan pentingnya penghematan energi. Surabaya sebagai salah satu kota metropolitan dengan kepadatan penduduk yang cukup tinggi juga tak luput dari tantangan tersebut. Tumbuh menjadi kota yang ekologis, ramah lingkungan dan manusiawi tidaklah mudah dan butuh kerja sama yang baik antara pemerintah, pengelola sector dan masyarakat. Pendekatan walikota Surabaya dan sosialisasi tentang pentingnya penerapan green architecture pada tiap kawasan berhasil menumbuhkan kesadaran masyarakat untuk menciptakan lingkungan yang harmonis, ekologis serta sadar energi. Selain aspek ekologis, yng menjadikan Surabaya sebagai kota termaju di Indonesia adalah pertumbuhan ekonomi. Pertumbuhan ekonomi yang pesat tak lepas dari motivasi Walikota Surabaya dalam menumbuhkan industri kecil dan menengah. Kampung Gundih merupakan salah satu kampung yang berhasil menerapkan implementasi konsep ekologis dan menjadi kampung industri termaju di Surabaya dengan memenangkan Surabaya Green and Clean beberapa tahun terakhir. Penelitian ini bertujuan untuk mengidentifikasi dan mendeskripsikan penerapan Green architecture dan konsep ekologis pada permukiman yang berbasis industri kecil di Kampung Gundih Surabaya.

Metode yang dilakukan dalam penelitian ini adalah deskriptif kualitatif. Hasil yang diperoleh adalah tinjauaan dari implementasi konsep arsitektur ekologi pada kawasan perkampungan dan industri kecil, deskripsi proses manajemen air terpadu, serta strategi pengelolaan lingkungan pada Kampung Gundih Surabaya.
\end{abstract}

Kata Kunci: Arsitektur Ekologi ; Industri kecil ; Kampung ; Manajemen lingkungan 


\section{PENDAHULUAN}

Revolusi Industri di Inggris yang terjadi beberapa abad lalu telah mempengaruhi berbagai sektor termasuk arsitektur dan sosial. Modernisasi dan tuntutan hidup yang serba praktis membuat selera masyarakat akan pola, tipe dan desain bangunan bergeser, termasuk pada bangunan dengan fungsi hunian. Begitu juga yang terjadi di Indonesia, masyarakat Indonesia yang tadinya agraris dan maritimberangsur berpindah ke sektor industry dan kota mengalami perkembangan yang pesat (Samsul, 2005). Pertumbuhan energi Indonesia relatif besar, penghematan dapat dilakukan dengan penataan kawasan yang baik serta implementasi konsep dan panduan perancangan arsitektur ekologis yang tepat (Priyatman, 2002 \& Heerwagen, 2004). Desain bangunan yang baik dapat menghemat energy hinga 2,5 kali lipat (Baker\&Steemers, 2005).

Industrialisme yang terjadi di kota mengakibatkan banyaknya masyarakat yang berpindah dari desa ke kota sehingga kepadatan di kota makin besar. Hal ini meningkatkan juga kebutuhan ruang hunian untuk penduduk kota, di sisi lain daya dukung ruang kota terbatas sehingga hal ini meyebabkan harga tanah di perkotaan semakin tinggi. Tingginya harga tanah di perkotaan membuat masyarakat baik dari sektor pemerintah maupun swasta memilih membangun bangunan bertingkat unntuk segala fungsi termasuk sektor hunian. Laju Urbanisasi yang besar ini membuat kebutuhan perumahan meningkat (Tanuwidjaja, et all, 2009). Pengembangan kawasan tidak bole lepas dari karakter budaya dan karakter masyarakatnya (Sulistyo, dkk, 2018)

Pertumbuhan ekonomi sebuah kota harus tetap mengacu pada karakter kawasan dan ekologis lingkungan. Pemkot Surabaya megembangkan kota dengan menmbuat beberapa programpemberdayaan masyarakat guna meningkakan kualitas ekonomi dan lingkungan dengan mendorong pengembangan industry kecil dan menengahdengan tidak meninggalkan konsep ekologis. Salah satu cara pemerintah kota dengan mengadakan sayembara berjudul "Surabaya Green and Clean". Kampung Gudih adalah salah satu kampong percontohan di Surabaya yang berhasil maju di sektor industri tanpa meninggalkan aspek ekologis kawasan.

Penelitian ini bertujuan untuk mengidentifikasi dan mendeskripsikan penerapan Green architecture dan konsep ekologis pada permukiman yang berbasis industri kecil di Kampung Gundih Surabaya.

\section{METODE}

Berdasarkan literature yang ditulis oleh Groat \& wang (2002) seecara umum metode yang dilakukan dalam penelitian ini adalah metode studi kasus, dimana terdapat sebuah kegiatan ilmiah yang dilakukan secara intensif dan terinci pada suatu objek studi dalam hal ini kelompok masyarakat di kampung Gundih Surabaya. Taktik yang dilakukan antara lain:

a. Pengamatan terhadap aspek arsitektural, sosial, ekonomi dan budaya pada lokasi penelitian

b. Analisis data, data yang diperlukan antara lain: peraturan setempat yang merujuk pada perilaku ekologis di masyarakat, implementasi aturan pada kegiatan seharihari masyarakat, kemudian dilakukan cross check pada benchmark yang sudah dibuat oleh Green Building Council Indonesia mengenai lingkungan hijau (green environtment)

c. Interview pada ketua RW, ketua RT dan beberapa masyarakat (pelaku usaha dan penduduk) mengenai penerapan green architecture pada tempat usaha dan tempat tinggalnya

Seperti yang telah dikemukakan oleh Mudjia (2017), penelitian studi kasus berfokus pada peristiwa kontemporer pada vaiabel yang diteliti. Variabel dan indikator yang diamati dalam penelitian ini antara lain penerapan konsep ekologis pada Kampung Gundih Surabaya, Manajemen Air dan lingkungan pada kampung Gundih, Karakter permukiman dan citra kawasan kampung Gundih, dan industry kecil yang berkembag di kampung Gundih Surabaya.

Kampung Gundih dipilih sebagai objek studi kasus karena selama dua tahun berturutturut kampung ini menyandang gelar kampung industry terbaik dan memenangkan piala Green and Clean dari Wali kota Surabaya. Kampung ini dinilai berhasil merubah citra kawasan yang kumuh, padat penduduk dan tidak ramah 
menjadi kampung yang bersih, sehat, dan maju. Pengumpulan data dilakukan dengan cara survey lapangan dan studi literatur. Survey dilakukan pada tahun 2020. Analisis dilakukan dengan memberikan deskripsi dari indikator yang ada.

\section{HASIL DAN PEMBAHASAN}

\subsection{Deskripsi Umum Kampung Gundih Surabaya}

Kota metropolitan lekat dengan image macet, semrawut, padat dan tidak ramah lingkungan. Hal ini karena pada kota metropolitan biasanya terjadi pengembangan Industri secara besar-besaran yang mengakibatkan naiknya jumlah penduduk pada suatu kota. Industrialisasi memicu perpindahan penduduk dari desa ke kota, peningkatkan kepadatan kota menyebabkan penghuni kota makin heterogen dan pengendalian kawasan yang heterogen ini bukan sesuatu yang mudah (Tanuwidjaja, dkk, 2009).

Menurut Azizah (2016) citra suatu kota berkaitan dengan karaker dan jati diri kawsan tersebut. Cira kawasan bergantung dari kesan pengamatdalam menyeleksi, mengorganisir, serta menyimpulkan sehingga lingkungan yang diamati memberikan sebuah interpretasi hubungan yang khas. Ke-khas-an sebuah kawasan bergantung pada:

- Identitas objek yang diamati

- Struktur atau pola saling hubung antara pengamat degan objek yang diamati

- Makna atau interpretasi objek tersebut

- Elemen pembentuk citra kota antara lain: path (jalur), edges (batas), Districts (kawasan), Nodes (simpul) dan Landmark (simbol).

Laksmiyanti \& Salisnanda (2018) menjelaskan bahwa Surabaya yang berupa kota pesisir memiliki karakter iklim mikro yang cukup panas. Temperatur yang tinggi, radiasi matahari yang cukup besar dan kecepatan angina yang rendah membuat citra kota Surabaya sebagai kota yang panas semakin kuat, namun persepsi ini tidak seluruhya benar. Iklim mikro yang seolah tidak menguntungkan ini dapat dimanfaatkan oleh arsitek dengan mendesain bangunan yang mampu mengoptimalkan kondisi iklim yang ada sehingga dapat tercipta bangunan atau kawasanyang sehat dan hemat energi.
Pada tahun 1990-an memang Surabaya lekat dengan image kota yang panas. Kampung Gundih juga menjadi salah satu zona merah atau area rawan preman (Agustina \& Mahbub, 2019). Hingga pada tahun 2015 pemerinta kota Surabaya mulai mengembangkan sejumlah kampung dengan pembagian sebagai berikut: kampung Unggulan, kampung wisata, kampung lingkungan dan ilmu. Kampung Gundih ini terkenal dengan adanya beberapa industry kecil antara lain: industri kue basah dan wingko, industri briket arang, industri pupuk kompos dan industri daur ulang sampah.

Kampung Gundih ini terletak di Surabaya Utara. Merupakan kampung yang padat penduduk berlokasi di kecamatan Bubutan kelurahan Gundih. Dulu kawasan ini merupakan kawasan yang padat dan kumuh, namun upaya pengembangan kawasan yang dirintis sejak tahun 1990-an oleh pengelola kampug saat ini telah membuahkan hasil.
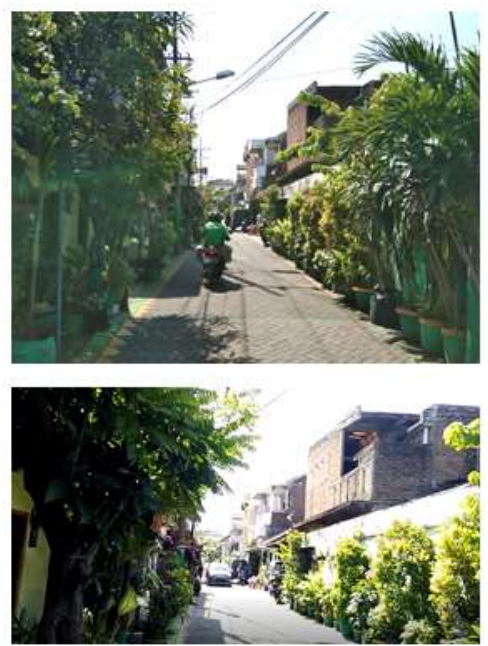

Gambar 1. Kondisi kampung Gundih tahun 2020 sebagai kampung terbaik di Surabaya. (sumber:

Dokumentasi pribadi)

Penghargaan yang diperoleh kampung ini antara lain:

- Kampung dengan sanitasi terbaik, diberikan oleh Walikota Surabaya pada bulan September tahun 2017

- Pemenag Surabaya Green and Clean, kampung dengan pengelolaan lingkungan terbaik, diberikan oleh Walikota Surabaya pada bulan Desember tahun 2017

- Pemenang lomba kreasi daur ulang (botol) 


\subsection{Upaya Penerapan Eco Architecture pada Kawasan Kampung Industri Kecil}

Green Building Council Indonesia telah membuat benchmark utuk kawasan hijau. Upaya pertama yang dilakukan kampung Gundih adalah Menjaga keserasian dan keseimbangan ekosistem lingkungan, serta meningkatkan kualitas lingkungan kawasan yang sehat. Langkah kongkrit dalam hal ini yang telah ditempuh oleh kampung Gundih adalah dengan:

a. Peraturan untuk memilih sampah dan membuang sampah pada tempatnya

b. Setiap rumah wajib meyediakan bak sampah di halaman depan

c. Setiap rumah diwajibkan melaksanakan penghijauan, terdapat denda untuk pembelian bibit pohon bagi keluarga yang tidak melaksanakannya

d. Penghijauan di lahan sempit dengan metode tambulampot dan hidroponik

e. Ada komposter di beberapa titik

f. Terdapat bank sampah

g. Terdapat pengelolaan air limbah (Grey Water) secara terpadu dengan mengolah air hujan menjadi air yang digunakan kembali

h. Terdapat lubang biopori
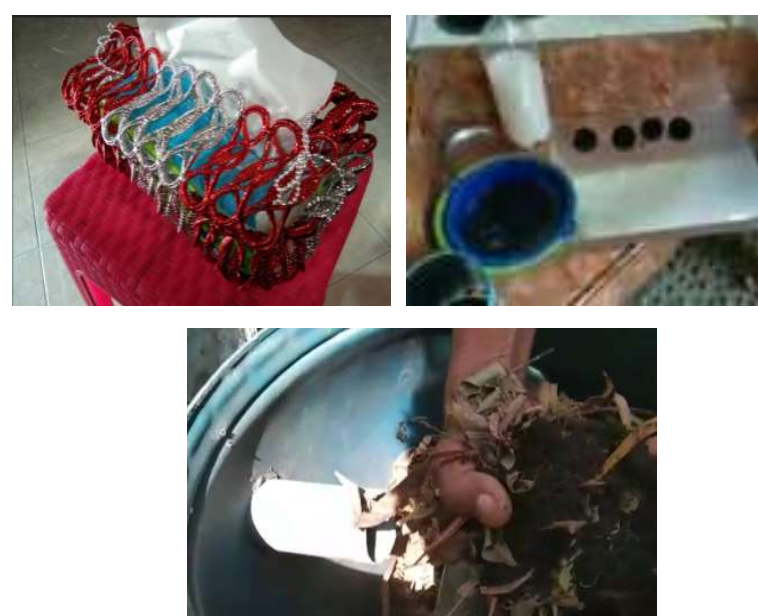

Gambar 2. Hasil dari home industry kapung Gundih: barang dari daur ulang sampah, briket arang batok, pupuk kompos. (sumber: Dokumentasi pribadi)

Warga kampung Gundih meyadari pengembangan industri kecil di kawasannya menimbulkan dampak negatif bagi lingkungan maka dari itu untuk setiap industri yang ada diwajibkan memiliki pengelolaan limbah mandiri. Pengelolaan sampah yang baik sudah dimulai di tiap rumah. Sampah organic dikumpulkan di komposter yang tersebar di bberapa titik, sampah anorganik disetorkan di bank sampah yang kkemudian diolah oleh industry daur ulang yang ada di kawasan tersebut. Industri pengolahan bahan bekas yang ada telah memproduksi bahan pakai seperti: tas, tempat pensil, pajangan dan benda seni dari bahan bekas.

Peningkatan kualitas iklim mikro pada kawasan ini dilakukan dengan membuat lubang biopori dan melakukan rain water harvesting. Lubang biopori dibuat dengan tujuan:

a. Megatasi banjir

b. Menambah daya resap tanah

c. Meningkatkan kualitas tanah dengan adanya aktivitas biota tanah

d. Meningkatkan kawasan hijau

Jalan yang sempit, rumah penduduk yang padat membuat kampung ini memiliki resapan yang sedikit, dengan adanya lubang biopori maka memungkinkan untuk menambah area resapan pada kawasan.

Pengelolaan air secara terpadu juga dilaksanakan di kampung ini dengan menampung air hujan dan grey water dari warga ke dalam tendon bawah tanah. Air hujan dari tendon ini kemudian disaring melalui beberapa filter dan dialirkan ke rumah warga dan beberapa bangunan publik seperti Masjid, PAUD, balai RW seingga penggunaan air dari PDAM dapat dihemat.

Kampung ini juga menerapkan asas keterhubungan, kemudahan pencapaian, keamanan, dan kenyamanan pada jalur pejalan kaki. Jalan kampung ini tidak lebar, hanya dapat dilewati 1 mobil dan motor (lebar jalan 6m).Maka pengelola kampung menerapkan kebijakan dilarang parkir di jalan bagi pemilik kendaraan pribadi baik itu mobil maupun motor. Selain untuk menigkatkan kenyamanan pengunjung hal ini juga bertujuan agar jika sewaktu-waktu terjadi kondisi darurat seperti kebakaran atau warga membutuhkan ambulance secara cepat, mobil dapat lewattanpa ada hambatan. Sistem lalu lintas yang dibuat searah dengan memasang berbagai plank atau papan penunjuk jalan di setiap simpul dan elemen penanda yang jelas membuat pejalan kaki dan pengunjung dengan mudah mencapai tujuannya di kawasan ini.

Upaya menjaga keseimbangan antara kebutuhan dan ketersediaan sumber daya di masa mendatang dilakukan dengan beberapa langkah kongkrit antara lain: 
a. Mendorong produksi pangan lokal dan mengurangi jejak karbon yang berasal dari emisi transportasi penyediaan pangan. Salah satu akibat dari aksi ini adalah tumbuhnya bberapa industry makanan rumahan di kampung tersebut.

b. Menyediakan lahan untuk produksi sayur dan buah lokal untuk memenuhi kebutuhan masyarakat setempat. Sosialisasi pemanfaatan lahan sempit dengan penghijauan menggunakan metode tambulampot dan hidroponik serta kewajiban menanam tanaman toga pada setiap rumah mendukung hal ini.

c. Menyelenggarakan promosi gaya hidup berkelanjutan kepada masyarakat di dalam kawasan. Green architecture dapat dicapai dengan optimal jika gaya hidup masyarakat mengarah pada konsep ekologis. Ketertarikan pada produk lokal, kesadaran pengolahan sampah dan kedaran 3R (reduce, reuse, dan recycle) perlu dikembangkan.

d. Membangun kawasan dengan memperhatikan pelestarian dan pengembangan budaya lokal. Kampung Gundih cukup aktif mengikuti kegiatan yang diadakan oleh pemkot Surabaya seperti lomba, festival dan parade. Pengurus kampung tak segan menganggarkan dana yang cukup besar untuk ini agar masyarakat mau berpartisipasi. Hal ini dilakukan agar generasi muda tidak lupa akan sejarah, tetap mengenal identitas "arek suroboyo" guna mempertahankan budaya dan citra kawasan.

\subsection{Pembahasan}

Lingkungan yang sustainable adalah lingkungan yang layak huni, dengan mempertimbangkan aspek Ekonomi, Ekologi, dan Humanity, hal ini tertuang dalam Agenda 21 (Kementerian Lingkungan Hidup, 1997) dalam poin sebagai berikut:

a. Pemerataan dan keadilan sosial. Pemerataan dalam distribusi sumber lahan dan faktor produksi, peran dan kesempatan perempuan serta pemerataan ekonomi yang dicapai dengan keseimbangan distribusi kesejahteraan.

b. Keanekaragaman (diversity) Pemeliharaan aneka hayati sebagai prasyarat untuk memastikan bahwa sumber daya alam selalu tersedia secara berkelanjutan baik untuk saat ini maupun masa mendatang. c. Integratif Kompleksitas keterkaitan antara antara sistem alam dan sistem sosial.

d. Perspektif jangka panjang

Menjadi lingkungan yang sustainable dapat dirangkum dalam istilah "SHE", yaitu Smart, Humane, and Ecological. Yang dimaksud dengan smart disini adalah manusia bergaya hidup cerdas, sarana bagi kegiatan penghidupan yang cerdas. Disebut kawasan yang humane atau manusiawi jika warga mengembangkan cita-cita hidup dan ada tempat di kota untuk mewujudkannya. Ekologis jika kawasan tersebut ramah lingkungan, dan ada keragaman hayati, hemat energi, cagar budaya terlindungi hingga mutu iklim nyaman.

Menurut Newman \& Jennings (2008) untuk mendapatkan predikat lingkungan yang sustainable dapat dikembangkan dengan 10 strategi berikut ini:

1. Visi

Memberikan visi jangka panjang untuk kota berdasarkan keberlanjutan; keadilan antargenerasi, sosial, ekonomi, dan politik; dan individualitas mereka.

2. Ekonomi dan aspek sosial

Mencapai jaminan ekonomi dan sosial jangka panjang.

3. Biodiversitas

Mengenali nilai intrinsik keanekaragaman hayati dan ekosistem alam, serta melindungi dan memulihkannya.

4. Jejak ekologis (ecological footprints)

Memungkinkan komunitas untuk meminimalkan jejak ekologis mereka.

5. Model kota dan ekosistem

Dibangun berdasarkan karakteristik ekosistem dalam pengembangan dan pemeliharaan kota yang sehat dan berkelanjutan.

6. Sense of place

Mengenali dan membangun ciri khas kota, termasuk nilai kemanusiaan dan budayanya, sejarah, dan sistem alamnya.

7. Pemberdayaan

Memberdayakan orang dan mendorong partisipasi.

8. Partnership

Memperluas dan memungkinkan jaringan kerja sama untuk bekerja menuju masa depan bersama yang berkelanjutan.

9. Produksi dan konsumsi berkelanjutan Mendukung produksi dan konsumsi yang berkelanjutan melalui penggunaan 
teknologi yang berwawasan lingkungan dan pengelolaan permintaan yang efektif.

10. Sistem Pemerintahan

Memungkinkan peningkatan berkelanjutan berdasarkan akuntabilitas, transparansi, dan tata kelola yang baik.

\subsection{Saran Pengembangan Bagi Kawasan Industri Kampung Gundih}

Secara umum upaya ekologis yang sudah dilakukan oleh Kampung Gundih cukup baik. Guna melakukan peningkatan berikut ini saran yang dapat diimplementasikan di kampung tersebut:

a. Menyediakan parkir bersama. Belum ada fasilitas ini di kampung tersebut sementara kepadatan kampung cukup tinggi. Parkir bersama dapat dibangun di lahan negatif atai mengoptimalkan bangunan yang tidak berfungsi

b. Penyediaan jalur sepeda pancal

c. Membuat diagram skematik air kawasan (air bersih dari PDAM, tanah, air alternatif seperti air danau, air hujan dan air daur ulang). Sudah ada pengelolaan air secara terpadu, namun analisa dan pencatatan belum dilakukan secara seksama. Jika ini dilakukan maka pengguaan air daur ulang akan lebih optimal.

d. Pengoptimalan penggunaan energy surya belum diterapkan di kampung ini. Potensi iklim tropis lembab selain curah hujan yang tinggi adalah radiasi matahari yang cukup besar. Energy yang diperoleh dari panas matahari dapat dikelola secara terpadu dan dimanfaatkan untuk bangunan publik. Industri kecil yang tumbuh di kampung ini juga dapat menjadikan panas matahari sebagai sumber energy alternatif.

\section{KESIMPULAN}

Lingkungan hijau yang ekologis pada kampung industri di Surabaya (kampung Gundih) secara umum diperoleh dengan strategi sebagai berikut (a) Menjaga keserasian dan keseimbangan ekosistem lingkungan, serta meningkatkan kualitas lingkungan kawasan yang sehat, (b) Meminimalkan dampak pembangunan terhadap lingkungan, Meningkatkan kualitas iklim mikro, (d) Menerapkan asas keterhubungan, kemudahan pencapaian, keamanan, dan kenyamanan pada jalur pejalan kaki, dan (e) Menjaga keseimbangan antara kebutuhan dan ketersediaan sumber daya di masa mendatang

\section{DAFTAR PUSTAKA}

Azizah Siti (2016), Pemanfaatan Teknologi Pada Produk Unggulan Untuk Mendukung Citra Kawasan. Seminar Nasional Pendidikan 2016: Unversitas Jember

Baker Nick dan Koen Steemers (2005), Energy and Environmental in Architecture, Taylor \& Francis Group, New York

Bahri Samsul (2005), Rumah Susun Sebagai Bentuk Budaya Bermukim Masyarakat Modern, Jurnal Sistem Teknik Industri: Vol. 6, no. 3, hh. 97-102

Green Building Council Indonesia (2015), Greenship Rating Tools untuk Kawasan versi 1.0, Jakarta: Direktorat Pengembangan Perangkat Penilaian

Groat Linda \& Wang David (2002), Architectural Research Methods, John Wiley \& Sons, Inc, Canada

Gunawan Tanuwidjaja, Mustakim, Maman Hidayat, Agus sudarman (2009), Integrasi Kebijakan Perencanaan dan Desain Rumah Susun yang Berkelanjutan, dalam Konteks Pembangunan Kota yang Berkelanjutan, Seminar Nasional Univ.Kristen Maranatha, Bandung

Heerwagen Dean (2004), Passive and Active Environmental Controls Informing The Schematic Design of Building, Mc Graw Hill, New York

Kementerian Lingkungan Hidup (1997), Ringkasan Agenda 21 Indonesia (Strategi Nasional Untuk Pembangunan Berkelanjutan), Jakarta : Kantor Menteri Negara Lingkungan Hidup

Laksmiyanti Dian P.E \& Salisnanda Randy P (2018), Optimization of skylight composition for cooling and lighting energy efficiency (Case Study: G-building ITATS), International Journal of Advanced Engineering Research and Science (IJAERS), Vol-5, Issue-11, hh. 266-271

Melani Agustina \& Harun Mahbub (2019), Kampung Gundih Surabaya Kawasan Preman Menjelam Jadi Kampung Hijau 
Opsi

Vol 14 No 1 June 2021

(https://surabaya.liputan6.com/read/4129 504/kampung-gundih-surabaya-kawasanpreman-menjelma-jadi-kampung-hijau), diakses tanggal: 2 November 2020

Newman Peter \& Jennings Isabella (2008), Cities as Sustainable Ecosystem Principles and Practice, Island Press, London

Priatman Jimmy, 2002, "Energy-Efficient Architecture" Paradigma Dan ManifestasiArsitekturHijau. FT UKPetra: Dimensi Teknik Arsitektur vol 31 no 1
Rahardjo Mudjia (2017), Studi Kasus Dalam Penelitian Kualitatif: Konsep dan Prosedurnya (http://repository.uinmalang.ac.id/1104/), diakses tanggal: 28 November 2020

Sulistyo B W, Antariksa, Surjono, Hakim L (2018), A Comparative Study of Public Open Space Handling Methodology in Urban Area. Jrnal IPTEK no 6 vol. Surabaya: Institut Teknologi Adhi Tama 